\title{
Maxillary First Premolar with Three Canals: An Endodontic Challenge
}

\author{
Dr. T. M. Mangala ${ }^{1}$, Dr. Nilam Kadam ${ }^{2}$, Dr. Adish Saraf ${ }^{3}$, Dr. Sneha Mali ${ }^{4}$, Dr. Ajinkya Gharge ${ }^{5}$, \\ Dr. Sabina Shiakh ${ }^{6}$
}

Department of Conservative Dentistry and Endodontics, School of Dental Sciences, K.I.M.S.D.U, KARAD, Maharashtra, India

\begin{abstract}
A thorough knowledge about the normal and abnormal variation of anatomy of the teeth and their detection is essential for clinical success. Maxillary first premolars show a considerable variation in root canal morphology but the presence of three roots is rare. The maxillary first premolar is the most commonly bi- rooted tooth with occasional presentation of three roots system; it is a transitional tooth between incisors and molars. Although it usually has two canals, it may rarely have three and this third canal can easily be missed. However, it must be taken considered radiographically and clinically during endodontic treatment. This article describes the diagnosis and clinical management of two cases of maxillary first premolar with three separate roots and three root canals with special reference to radiographic interpretation, dental operative microscope and diagnosis.
\end{abstract}

Keywords: Root canal anatomy, Maxillary $1^{\text {st }}$ Premolar, Three roots, Three canals, Electronic apex locater, Dental operative microscope.

\section{Introduction}

The maxillary $1^{\text {st }}$ premolar is most commonly bi-rooted tooth with incidence of $56 \%$.about $40 \%$ have only one root containing two canals that then unite in a common foramen. ${ }^{1}$ According to vertucci et al a maxillary $1^{\text {st }}$ premolar with three separate roots can be observed in $5 \%$ to $6 \%$ of the cases and $1 \%$ for second premolars. ${ }^{2,3} 1^{\text {st }}$ premolar to have 3 canals $-0.5 \%$ existed as 3 canals in a single root, $0.5 \%$ existed as 2 canals in one root,ans 1 canal in a $2^{\text {nd }}$ Root, and $4 \%$ existed as one canal in each of 3 seperated roots. Corns and Skidmore found 6 of 100 maxillary $1^{\text {st }}$ Premolar to have 3 canals ,all of which existed as 1 canal in each of 3 roots ${ }^{3}$.vertucci et.el found 2 of 200 maxillary $2^{\text {nd }}$ premolar to contain 3-canals. ${ }^{4}$

To achieve successful endodontic treatment it requires effective biomechanical preparation of root canals and 3dimensional obturation of the root canal system. Thus meticulous knowledge of the tooth morphology ,proper interpretation of angled radiographs, proper access cavity preparation with modifications if required and use of advanced dental tools like endodontic microscopes are essential.

Insufficient knowledge of the anatomy of the teeth will lead to failure of root canal therapy. The anatomy of maxillary premolar with 3 root canals mesiobuccal, distobuccal and palatal is similar to that of adjacent maxillary molars and they are therefore sometimes called as small molars or ridiculous. In straight on radiographs of maxillary premolar sieraski et .el found that whenever the mesio-distal width of the mid-root image is equal to or greater than the mesiodistal width of the crown the tooth most likely has 3-roots ,based on this information we diagnosed and processed with endodontic treatment of patient with 3 canalled and 3-rooted maxillary first premolars.

This article was to report one case with three roots and three canals maxillary $1^{\text {st }}$ premolar.

\section{Case Report}

19 year old female patient with non contributory medical history reported to Dept.of Conservative Dentistry and Endodontics of school of dental sciences, karad.

She had history of sharp pain in maxillary right premolar teeth region on having sweet and on food impaction. Considerable tooth destruction by caries was visible distal surface of the tooth and part of the central fissure of the tooth .The x-ray (fig.1)inspection shows 2-roots but due to the overlapping of shades their apical configuration is not clear enough and the presence of $3^{\text {rd }}$ root canal has not been assumed.

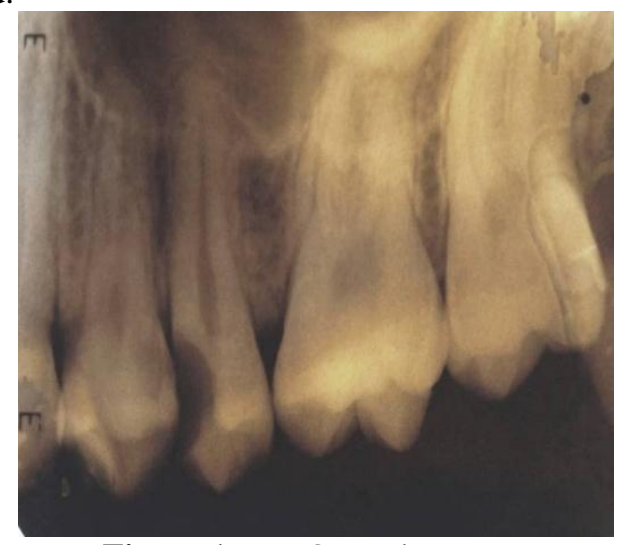

Figure 1: Pre-Operative x-ray

The tooth was diagnosed as chronic irreversible pulpitis and endodontic treatment was instituted .After local anaesthesia and rubber dam isolation of the operative area, pulp chamber area access was performed using an endoaccess bur. Next, the root canal orifices were located with no.10k file (Dentsply Maillefer, Ballaigues, Switzerland)with the aid of dental operating microscope(fig.2) to facilitate visualisation. 


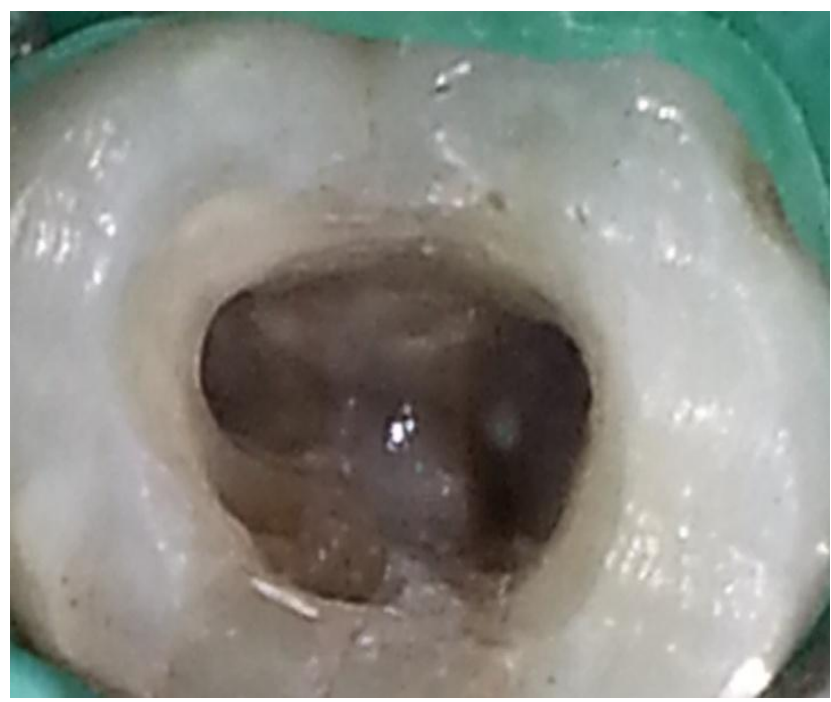

Figure 2: DOM image

At each change of instrument, the canals were irrigated with $2.5 \% \mathrm{NaOCl}$.During root canal treatment presence of 3 canals were confirmed with the aid of electronic apex locater(, two canals in the buccal side that is mesio-buccal and disto-buccal, and third on palatal side.Working length estimated MB1-19 mm,DB-19mm,Palatal-20mm.(fig.3)

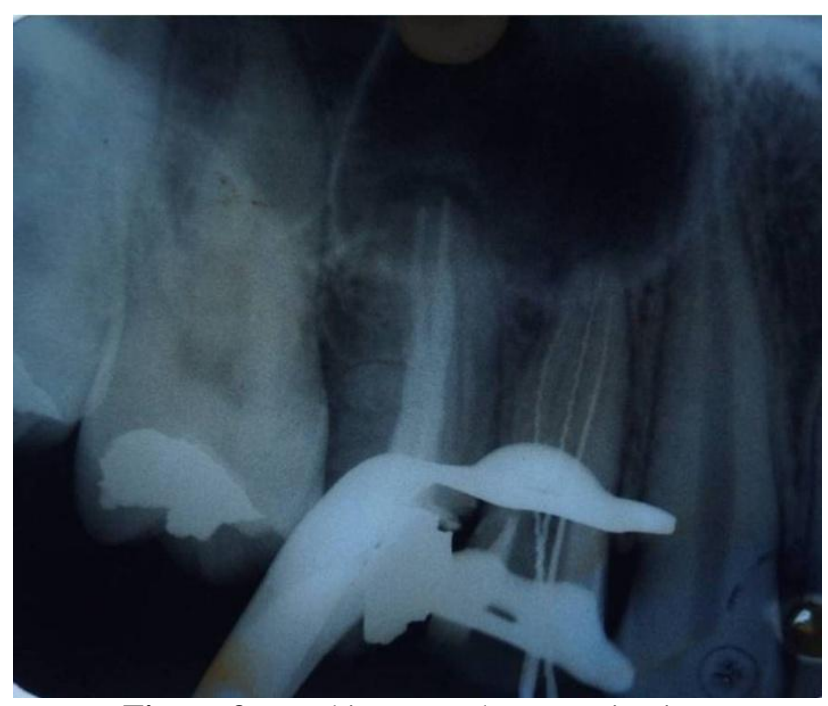

Figure 3: Working Length Determination

Revo- S (Micro-Mega,Besancon,France) rotary endodontic treatment files used for cleaning and shaping. Cervical preparation done with SU and apical with SC1 and SC2 in the buccal and palatal canals to an apical size 25 with 0.06 taper. RC Help (Prime Dental Products Pvt. Ltd.) was used in all canal preparations and irrigation with $2.5 \% \mathrm{NaOCl}$ was carried out using 27 gauge irrigating needle $3 \mathrm{~mm}$ from working length. At each engage of instrument $2 \mathrm{ml}$ of $2.5 \%$ $\mathrm{NaOCl}$ was used. When the instrumentation of root canal completed 17\% EDTA irrigation done for $3 \mathrm{~min}$ to remove smear layer. The canal was flushed again with $2.5 \% \mathrm{NaOCl}$ followed by final rinse with $5 \mathrm{ml}$ of saline solution. Finally, the root canals were dried with absorbent paper points and the root canals were then obturated with gutta percha and zinc -oxide eugenol sealer using lateral compaction technique.(fig 4\&5).

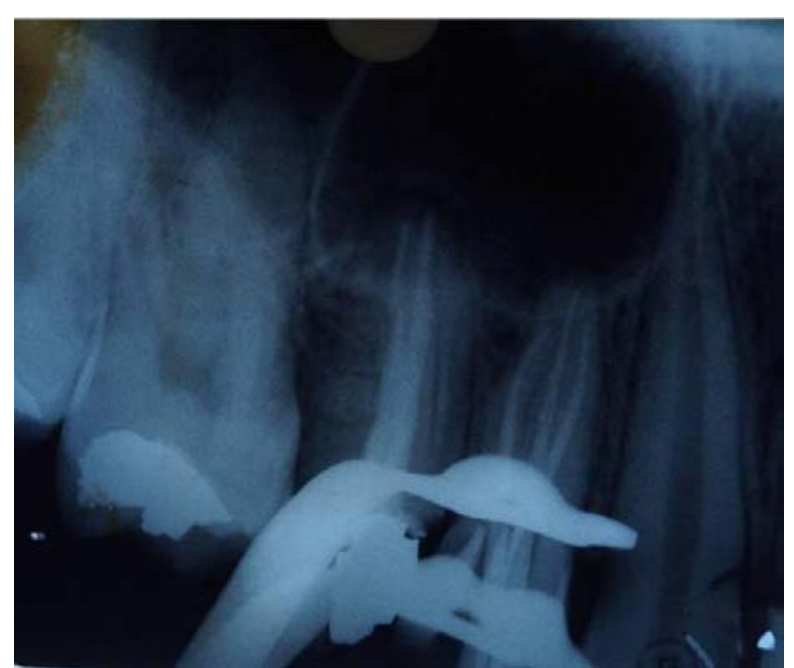

Figure 4: Master Cone

The pulp chamber was cleaned to remove excess of guttapercha and sealer and the tooth was restored with amalgam restoration.

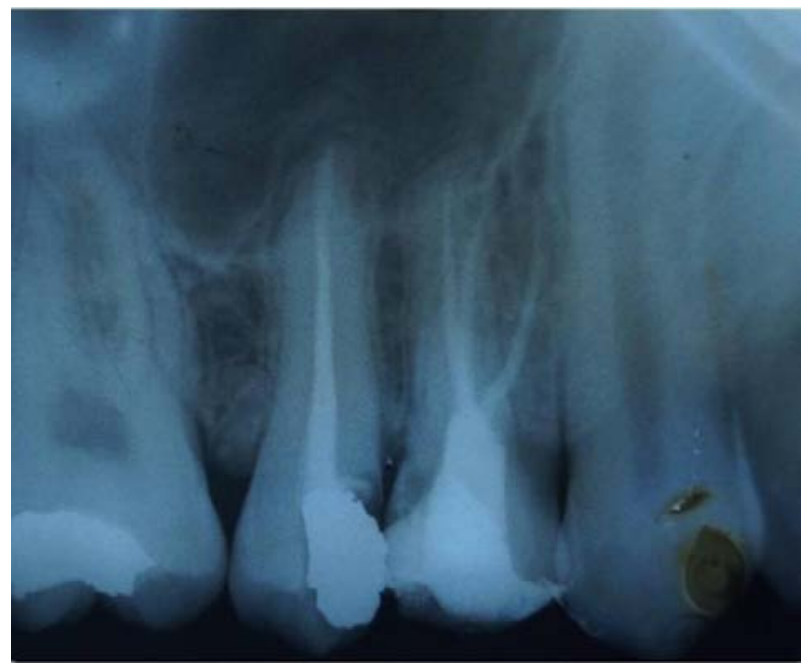

Figure 5: Obturation

\section{Discussion}

One of the major challenges in endodontic therapy is to treat teeth with variable anatomic configurations.

The careful examination of pre-operative radiographs is essential. In case of a doubt regarding possible variations in dental anatomy, two diagnostic X-ray images are recommended $^{1,8,9,10}$. If suddenly the X-ray image of a wide and well-shaped root canal narrows or disappears, it is as-sumed that there is a special root anatomy and probably a split of the root canal ${ }^{11,12,13 .}$

A three-canalled maxillary premolar requires an access cavity modification into a "T" shape mesio-distally extending the buccal aspect of the usual outline form. This modification allows good access to each of the two buccal canals ${ }^{7}$. The careful inspection of the shape of the pulp chamber might be a signal for a greater number of root canals. The buccal pulp horn is larger than the palatal pulp horn. The mean distance between the most cervical region of the pulp chamber roof and the canal bi-furcation and 


\section{International Journal of Science and Research (IJSR) \\ ISSN (Online): 2319-7064 \\ Index Copernicus Value (2013): 6.14 | Impact Factor (2014): 5.611}

trifurcation is 3.13 and $5.08 \mathrm{~mm} .{ }^{14}$ A thorough knowledge of variations will assist the dentist in reaching conclusions when diagnosing and treating endodontic cases. No technological advances or innovations can fully compensate for a lack of understanding of the anatomical features of the pulp chamber, which along with the root canal space are always located in the cross sectional centre of the crown and root respectively25. In the case presented, the crucial step in finding the additional buccal canal was careful tactile examination of the buccal wall with appropriate file size15. Following the location of these canals, special consideration was also given to the biomechanical preparation of the canals and subsequent obturation

to obtain a substantive hermetic seal. The location of canal orifices is best achieved with good illumination and a dry pulp floor. Magnification with either loupes or a microscope is usually considered beneficial; however the dental operating microscope (DOM) is usually better for detecting orifices. ${ }^{15,16}$

\section{Conclusion}

Morphological variations in pulpal anatomy must be always considered before beginning treatment. Careful clinical and radio graphical examination is essential for successful endodontic treatment. Use of an operating microscope or loop can enhance the visualization of the pulp chamber and extra canal orifices.

\section{References}

[1] Vertucci FJ. Root canal anatomy of the human permanent teeth. OralSurg Oral Med Oral Pathol. 1984 Nov;58(5):589-99.

[2] Vertucci FJ, Gegauff A. Root canal morphology of the maxillary first premolar. J Am Dent Assoc 1979;99:194198.

[3] Carns EJ, Skidmore AE. Configuration and derivatives of root canals of maxillary first premolars. Oral surg. 1973; 36:880-886

[4] Vertucci F, Seelig A, Gillis R. Root canal morphology of the human maxillary second premolar. Oral Surg 1974;38:456-464.

[5] Fishel D, Tamse A. Dentists' mistakes in making correct Periapical radiograph after obturation of the three radiographic diagnosis. Quintessence Int 1978;6:59-64.

[6] Kersten DD, Mines P, Sweet M. Use of the microscope in endodontics: results of a questionnaire. J Endod 2008;34:804-807.

[7] Sieraski SM, Taylor GT, Kohn RA. Identification and endodontic management of three-canalled maxillary premolars. J Endod 1985;15:29-32.

[8] Arizu HD, Alacam T. Diagnosisand treatment of threerooted maxillarypremolars. Eur J Dent. 2009 Jan;3(1):62-6.

[9] Karumaran CS, Gunaseelan R,Krithikadatta J.Microscope-aided endodontic treatment of maxillary first premolars with three roots: A case se-ries. Ind $J$ Dent R2011; 22(5):706-8.

[10] Nica L, Ianes C, Florita Z. Root canal treatment of a three-rooted maxillary first premolar -a case report. Endodontic Practice Today. 2011; 5(1):63-6.
[11] Topalova-Pirinska Sn, Kirilova J,Pirinska Đ. Radiographic investigation of root canal morphology of permanent premolars. Stomatologia. 2008: 90(2):98103. [in Bulgarian]

[12] Kirilova J, Chaucheva B,Razsipyiska İG. The case with three canals of first maxillary premolar. Problems of Dental Medicine. 2009;35(2):80- 2. [in Bulgarian]

[13] Kuzmanova Y. Prospective application of the clinical and X-ray analysis in endodontics. Stomatology 1998;80(1):63-68. [in Bulgarian]

[14] Vier-Pelisser FV, Dummer PM,Bryant S, Marca C, Só MV, Figueiredo JA. The anatomy of the root canal system of three-rooted maxillary premolars analysed using high-resolution com-puted tomogaphy. Inter Endod J. 2010Dec:43(12):1122-31.

[15]Bander A, Majed A, Shatha A, et al. Maxillary first premolar with three canals. Smile Dent. J. 2010;5(3): 3436

[16] Trope M, Elfenbein L, Trondstad L. Mandibular premolars with more than one root canal in different race groups. J. Endod 1986; 12: 343- 345. 